\title{
Long-term trend of Ulva prolifera blooms in the western Yellow Sea
}

\author{
Lin $\mathrm{Qi}^{\mathrm{a}}$, Chuanmin $\mathrm{Hu}^{\mathrm{b}, *}$, Qianguo Xing ${ }^{\mathrm{c}}$, Shaoling Shang ${ }^{\mathrm{a}}$ \\ a State Key Laboratory of Marine Environmental Science, Xiamen University, Xiamen 361102, China \\ ${ }^{\mathrm{b}}$ College of Marine Science, University of South Florida, 140 Seventh Avenue, South, St. Petersburg, FL 33701, USA \\ ${ }^{\mathrm{c}}$ Key Laboratory of Coastal Environmental Processes and Ecological Remediation, Yantai Institute of Coastal Zone Research, Chinese Academy of Sciences, 17 \\ Chunhui Road, Laishan District, Yantai, Shandong 264003, China
}

\section{A R T I C L E I N F O}

\section{Article history:}

Received 28 May 2016

Received in revised form 15 July 2016

Accepted 19 July 2016

Available online 12 August 2016

\section{Keywords:}

Ulva prolifera

Green tide

Remote sensing

MODIS

Aquaculture

Eutrophication

\section{A B S T R A C T}

Blooms of the green macroalga Ulva prolifera in the western Yellow Sea occurred every year since 2008, and they have been reported and studied extensively using a variety of means including remote sensing. However, to date, long-term bloom patterns have not been reported except for a few case studies showing examples in different years. Here, using MODIS observations and an objective method to perform statistical analysis, mean Ulva coverage in the western Yellow Sea has been derived and analyzed between 2007 and 2015 at both monthly and annual scales. On annual scale, mean Ulva coverage decreased after 2008, but increased rapidly after 2012 from $8 \mathrm{~km}^{2}$ in 2012 to $116 \mathrm{~km}^{2}$ in 2015 (the largest ever reported in history for this region). In the month of June the mean coverage increased from $18 \mathrm{~km}^{2}$ in 2012 to $363 \mathrm{~km}^{2}$ in 2015. Other than 2009 and 2010, the month of June showed maximum Ulva coverage in every year. These coverage estimates are significantly lower than previously reported values as they represent "pure" algae coverage after taking into account of partial pixel coverage. Several environmental factors were examined in an attempt to determine the reasons behind such long-term changes, yet the results are inconclusive, suggesting a strong necessity of further coordinated and multi-disciplinary researches.

(C) 2016 Elsevier B.V. All rights reserved.

\section{Introduction}

Macroalgae blooms of Ulva prolifera (also called green tides) in the western part of Yellow Sea (YS) off the Shandong Peninsula (China, see Fig. 1) have been reported in both refereed and gray literature as well as in national and international news media since 2008 when an unexpected bloom interfered with training activities of the Olympic sailing game off Qingdao, China (Hu and He, 2008). Since then, macroalgae blooms are observed in May-August period every year in this region. Numerous studies have documented their growth cycles, seasonality, transport patterns, and their linkage with local aquaculture, eutrophication, and ocean circulations (Hu et al., 2010; Liu et al., 2009, 2013; Wang et al., 2015). However, to date, although a number of studies used remote sensing to estimate their spatial distributions and temporal changes, nearly all focused on how to effectively detect the presence of the macroalgae (Cui et al., 2012; Hu, 2009; Hu et al., 2010; Keesing et al., 2011; Lee et al., 2011; Garcia et al., 2013; Bao et al., 2015; Xing and Hu, 2016). Several studies used individual

\footnotetext{
* Corresponding author.

E-mail address: huc@usf.edu (C. Hu).
}

images to show the maximum coverage during the bloom season or the maximum impacted water area to show the severity (Keesing et al., 2011; Hu et al., 2010; Garcia et al., 2013; Xu et al., 2014; Xing et al., 2015a,b). To our best knowledge there has been little attempt to quantify the Coverage of Pure Algae (CoPA, i.e., waters fully covered by algae without gaps) from coarse-resolution satellite measurements, not to mention documenting the shortterm changes and long-term trend of CoPA in a statistically meaningful way. These estimates, on the other hand, will ultimately affect interpretation of changes in total algae biomass and factors leading to such changes.

The technical challenges in obtaining CoPA come from three aspects: (1) how to obtain stable imagery against changing atmospheric and observing conditions for delineating algaecontaining and algae-free pixels; (2) how to unmix a coarse pixel to derive a sub-pixel area covered by pure algae; and (3) how to generate reliable longer-term statistics from individual imagery, given the frequent cloud cover in the western YS. For quantifying algae coverage from individual pixels, normalization of algae pixels against nearby water pixels may remove most of the cross-image gradients in the same image (Keesing et al., 2011; Garcia et al., 2013). However, further normalization among different images is difficult. Shi and Wang (2009) developed a customized 

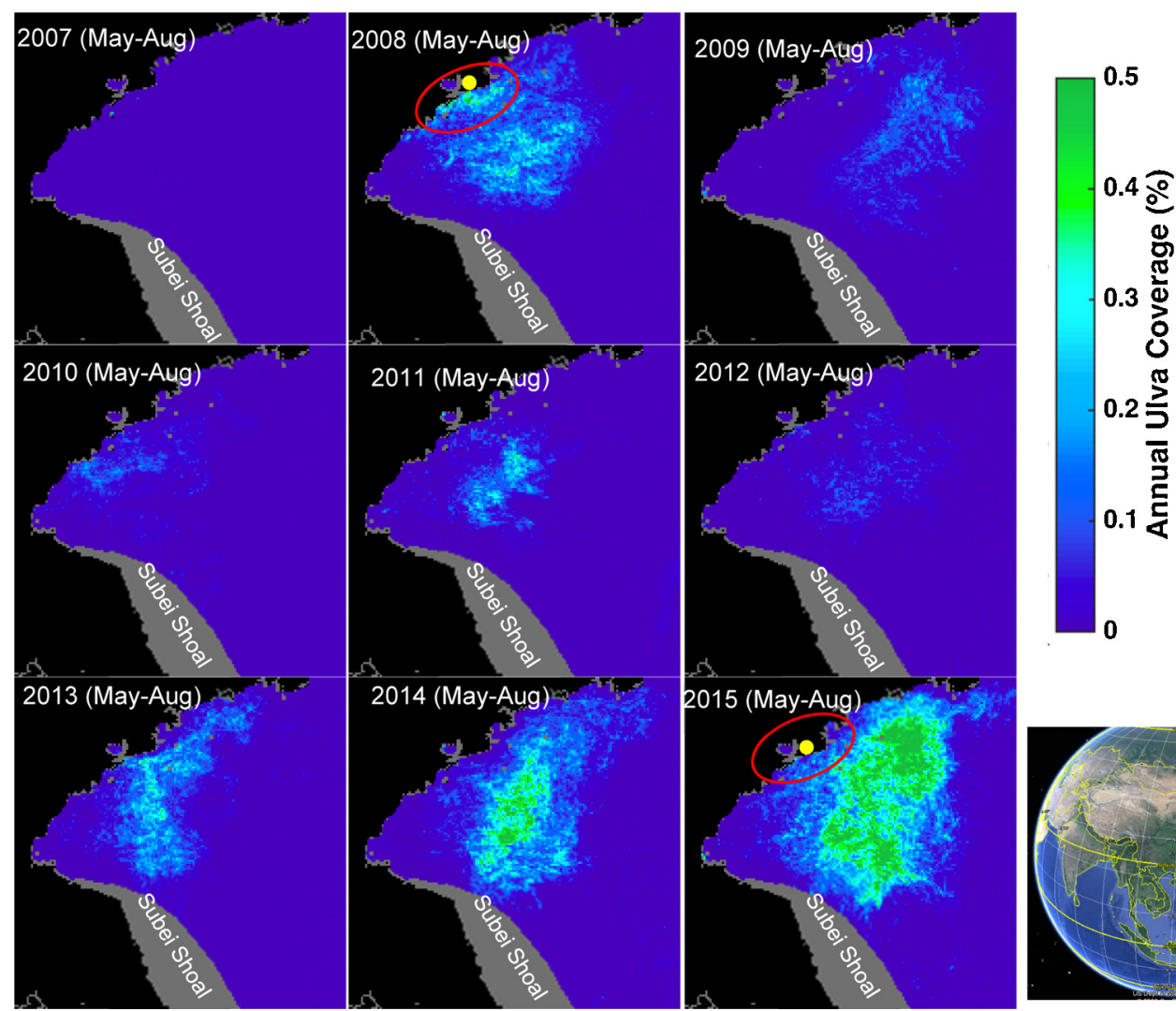

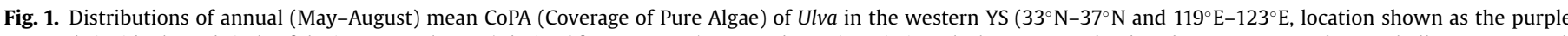

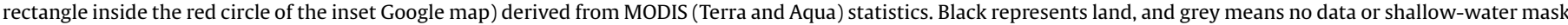

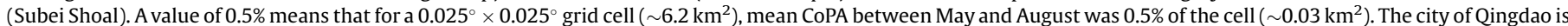

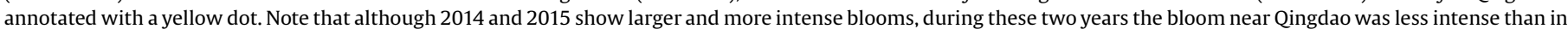
2008.

atmospheric correction to derive surface reflectance of the algae pixels so that cross-image comparison is made possible, yet the algae index is similar to the normalized difference vegetation index (NDVI) and therefore not linear to changes in sub-pixel coverage. Without a sophisticated atmospheric correction scheme as that used in Shi and Wang (2009), the Floating Algae Index (FAI) has been shown more tolerant than other indexes to changes in atmospheric and observing conditions ( $\mathrm{Hu}, 2009$ ), thus can be used to address the first challenge. Its linear subtraction design also makes it relatively easy to develop a linear unmixing scheme. Therefore, the objectives of this work are three folds: (1) to demonstrate a practical method to quantify pure algae coverage (i.e., CoPA) based on observations from the Moderate Resolution Imaging Spectroradiometer (MODIS); (2) to document the interannual changes and long-term trend of macroalgae coverage areas; and (3) to analyze what might cause such changes.

\section{Data and processing method}

The study region is located in the western Yellow Sea (YS), bounded by $33^{\circ} \mathrm{N}-37^{\circ} \mathrm{N}$ and $119^{\circ} \mathrm{E}-123^{\circ} \mathrm{E}$, a shallow marginal sea of the Pacific Ocean under the influence of the east-Asian monsoons. This region was selected because most of the Ulva macroalgae blooms occurred in this region (Hu et al., 2010; Xing et al., 2015a). All relevant data were selected to cover this region as well.

\subsection{MODIS data}

MODIS Level-0 data from both Terra and Aqua satellites over the study area (see Fig. 1) for all summer months (May-August) between 2007 and 2015 were obtained from the NASA Goddard Space Flight Center (OBPG, http://oceancolor.gsfc.nasa.gov). No data between 2000 and 2006 was obtained because previous studies (Hu et al., 2010; Xing et al., 2015a) showed no blooms in other months or other years for the western YS. Following $\mathrm{Hu}$ (2009), the data were processed using the SeaWiFS Data Analysis System software (SeaDAS, Version 7.0) to derive the Rayleighcorrected reflectance, $R_{\mathrm{rc}}(\lambda)$, in the spectral bands of $469,555,645$, 859 and $1240 \mathrm{~nm}$ for each image pixel. Then, all data were mapped to a cylindrical-equidistant (or rectangular) projection covering the study area. The $469-\mathrm{nm}, 555-\mathrm{nm}$, and $1240-\mathrm{nm}$ bands were resampled to $250-\mathrm{m}$ resolution to match the $645-\mathrm{nm}$ and $859-\mathrm{nm}$ bands.

For visualization, the spectral $R_{\mathrm{rc}}$ data were used to compose red-green-blue images. Two types of RGB images were generated, with the first being a natural true color (R: $645 \mathrm{~nm}$; G: $555 \mathrm{~nm}$; B: $469 \mathrm{~nm}$ ) and the second being a pseudo true color (R: $645 \mathrm{~nm}$; G: $859 \mathrm{~nm}$; B: $469 \mathrm{~nm}$ ). The difference in the pseudo true color image is that the $859-\mathrm{nm}$ band was used to replace the $555-\mathrm{nm}$ band, resulting in a greenish color for waters with macroalgae slicks due to their elevated reflectance at the $859-\mathrm{nm}$ band.

For each pixel, FAI was derived as (Hu, 2009)

$$
\begin{aligned}
& \mathrm{FAI}=R_{\mathrm{rc}, 859-R_{\mathrm{rc}, 859^{\prime}}} \\
& R_{\mathrm{rc}, 859^{\prime}}=R_{\mathrm{rc}, 645}+\left(R_{\mathrm{rc}, 1240}-R_{\mathrm{rc}, 645}\right) \times \frac{\left(\lambda_{859}-\lambda_{645}\right)}{\left(\lambda_{1240}-\lambda_{645}\right)},
\end{aligned}
$$

where the subscript numbers refer to band numbers. For MODIS, $\lambda_{1}=645 \mathrm{~nm} ; \lambda_{2}=859 \mathrm{~nm} ; \lambda_{3}=1240 \mathrm{~nm}$. FAI is basically the reflectance at $\lambda_{2}$ referenced against a linear baseline between $\lambda_{1}$ and $\lambda_{3}$. The linear subtraction design makes FAI more tolerant 
than NDVI to perturbations by aerosols, sun glint, thin clouds, and whitecaps (Hu, 2009). More importantly, the linear subtraction design makes it straightforward for linear unmixing a pixel when only partial algae coverage is found in the pixel (see below).

Between May and August of 2007-2015, each of the 2163 MODIS scenes over the study area was visually inspected through the truecolor, pseudo true-color, and FAI images. Of these, 357 scenes were found to contain macroalgae, but all images were used to quantify algae coverage using the method below.

\subsection{Environmental data}

Nutrient and pollutant data were obtained from the State Oceanic Administration (SOA) of China. Water samples along China coasts have been collected regularly by SOA, and the marine environmental parameters such as TIN and $\mathrm{PO}_{4}-\mathrm{P}$ are determined from water samples according to China's standard marine sampling and measuring protocols (GB17378.4-1998) (as presented by Xing et al., 2015b). These water sample data were then used to determine water quality levels and to estimate the area of polluted waters. On the basis of these data, an Area-Weighted Composite Pollution Index of Nitrogen and Phosphorus (AWCPINP) was proposed and used to quantify the water quality; subsequently the inter-annual variations in nutrient pollution level of a given region can be assessed with AWCPI-NP (Xing et al., 2015b).

The data of annual aquaculture area and production of the seaweed Porphyra yezoensis were obtained from the China Fisheries Year Book. Usually in summer of each year, local fisheries administration agencies from coastal provinces of China collect the detailed marine aquaculture data for the previous year, and then publish in the China Fisheries Year Book. The data include the cultured species, the corresponding area and production (e.g., seaweed $P$. yezoensis in the Jiangsu Province, China).

Level-3 monthly sea surface temperature (SST, ${ }^{\circ} \mathrm{C}$ ) and photosynthetically available radiation (PAR, Einstein $\mathrm{m}^{-2} \mathrm{day}^{-1}$ ) from 2003 to 2015 for the study region were obtained from the NASA ocean color Giovanni data portal (http://giovanni.gsfc.nasa. gov/giovanni/). These were gridded MODIS data at 4-km resolution. The data were averaged for the selected regions to form a time-series of monthly anomalies to examine the inter-annual variability and long-term patterns.

Both monthly precipitation data $\left(0.5^{\circ}\right.$ resolution $)$ from the TRMM Microwave Imager (TMI) and monthly wind speed at $10 \mathrm{~m}$ above sea surface from the MERRA model were obtained from the same NASA Giovanni data portal.

\section{Quantifying Ulva coverage}

Three steps were used to quantify mean Ulva macroalgae coverage for each month and for each year.

The first step is pixel classification. In the map projected FAI image, each pixel was classified as one of the three classes: Class 1 = no observation; Class $2=U l v a-$ containing pixel; Class $3=U l v a-$ free pixel.

Class 1 includes no-satellite coverage, land, land-adjacent pixels (dilation of $8250-\mathrm{m}$ pixels towards water to avoid land contamination of the satellite signal), extremely shallow water such as in Subei Shoal (which appears like land in the FAI image), severe sun glint, and clouds. In practice, this is achieved through two processes: (1) any pixel associated with the following conditions is regarded as having no observation:

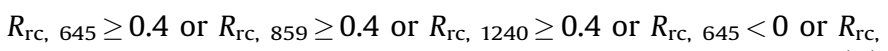

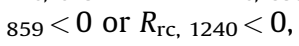

(2) after the above screening, any pixel associated with the following conditions is also regarded as having no observation:

$R_{\mathrm{rc}, 1240} \geq \mathrm{s} 1$ or $\left(R_{\mathrm{rc}, 469}>\mathrm{s} 2\right.$ and $R_{\mathrm{rc}, 645}>\mathrm{s} 3$ and $\left.R_{\mathrm{rc}, 859}>\mathrm{s} 3\right)$,

where $s 1=$ med_1240 +0.06, s $2=0.05$ and s3 $=$ med_ $1240+0.05$, and med_1240 is the median $R_{\mathrm{rc}}, 1240$ value of the entire image excluding the no-observation pixels using Eq. (2). In the above screening process, Eq. (2) excludes bright clouds or sun glint $\left(R_{\mathrm{rc}} \geq 0.4\right)$ and invalid pixels $\left(R_{\mathrm{rc}}<0\right)$, while Eq. (3) excludes those less-bright clouds through the use of threshold (s1) and $R_{\mathrm{rc}}$ spectral shape between 469,645 , and $859 \mathrm{~nm}$. This is basically the same approach as outlined in $\mathrm{Hu}$ (2011) but adjusted for the western YS study region. We want to emphasize that none of the published cloud masking methods (including the standard MODIS MOD35 cloudmask) worked well in the study region. They resulted in either too many false positives (e.g., treat Ulva pixels as clouds because they both have elevated NIR reflectance) or too many false negatives (e.g., treat thin clouds as no clouds). The above empirical criteria were a result of trial and error, which worked well for all 2163 MODIS images. Occasionally, there were still some $(<5 \%)$ false positive and false negatives as verified by visual inspection, but they were manually corrected.

After masking Class 1 pixels, Class 2 pixels were determined through the use of an FAI threshold $\left(\mathrm{FAI}_{\mathrm{L}}\right)$. This was achieved through several iterations for each image. $\mathrm{FAI}_{\mathrm{L}}$ was varied gradually until the delineated Ulva slicks (i.e., whose FAI values were $>F_{L} I_{L}$ ) agreed with both the FAI gradient image and the pusedo-RGB image when all images were linked together in the software ENVI. In essence, the visually-determined algae slicks were used as the truth. Note that similar to those demonstrated in Hu et al. (2010), although the total number of Ulva-containing pixels is sensitive to the choice of $\mathrm{FAI}_{\mathrm{L}}$, the CoPA after linear unmixing is not. Once Class 1 and Class 2 pixels were determined, the remaining pixels in an image were Class 3 pixels.

The second step is to unmix the Class 2 pixels. This is because each MODIS pixel is at least $250-\mathrm{m} \times 250-\mathrm{m}$ wide, and most (if not all) Ulva-containing pixels may be covered only partially by Ulva. The fractional algae coverage in the $i$ th Class 2 pixel $\left(\alpha_{i}\right)$ was determined from the following linear unmixing model

$\alpha_{i}=\frac{\left(\mathrm{FAI}_{i}-\mathrm{FAI}_{\mathrm{L}}\right)}{\left(\mathrm{FAI}_{\mathrm{H}}-\mathrm{FAI}_{\mathrm{L}}\right)}, \quad 0.0<\alpha_{i} \leq 1.0$,

where $\mathrm{FAI}_{i}$ is the FAI value of the $i$ th Class 2 pixel, $\mathrm{FAI}_{\mathrm{H}}$ is the upper bound of threshold representing $100 \%$ sub-pixel coverage. $\mathrm{FAI}_{\mathrm{H}}$ was determined from field-measured reflectance spectra from pure Ulva mat (Fig. 1.3 of He et al., 2011), modulated by the atmospheric transmittance and aerosol perturbation (Hu, 2009).

The last step is to calculate individual image algae coverage and monthly mean coverage statistics from the individual images after classifying each image pixel into one of the three classes and after determining the fractional algae coverage of the Ulva-containing pixels through pixel unmixing. For the individual image algae coverage, two estimates were derived. The first is the area covered by all algae-containing pixels, which was calculated as a simple summation of all algae-containing pixels:

$A_{\text {daily }}=N_{\mathrm{A}} \times 0.25 \times 0.25 \times \cos (35)\left(\mathrm{km}^{2}\right)$,

where $N_{\mathrm{A}}$ is the total number of algae-containing pixels in an individual image. The second is the CoPA after pixel unmixing:

$A_{\text {daily }}^{\prime}=\Sigma \alpha_{i} \times 0.25 \times 0.25 \times \cos (35)\left(\mathrm{km}^{2}\right)$,

where the summation is for all algae-containing pixels ( $i$ from 1 to $N_{\mathrm{A}}$ ). Note that when $\alpha_{i}=1.0$ for every pixel, Eq. (6) becomes Eq. (5).

Because of variable cloud cover in different days, it is difficult to compare daily algae coverage in a statistically meaningful way. For 
example, daily algae coverage (in $\mathrm{km}^{2}$ ) in a cloudy day may be a small fraction of that in a cloud-free day, but this does not mean that the former had less algae on the ocean surface. To overcome this difficulty, following the standard data binning approach of the U.S. National Aeronautics and Space Administration (NASA) (Campbell et al., 1995), the following statistics was used to calculate monthly mean algae coverage and annual mean coverage. In such calculations, the study region was divided into $0.025^{\circ}$ $\times 0.025^{\circ}$ grid cells. For each grid cell, all pixels falling in that cell within a month were used to estimate the mean percentage coverage of Ulva in that month as:

$f=\frac{\left[\Sigma \alpha_{i}\right]}{\left(N_{\mathrm{A}}+N_{\mathrm{W}}\right)}, \quad i=1$ to $N_{\mathrm{A}}+N_{\mathrm{W}}, \quad 0.0 \leq f \leq 1.0$,

where the summation is for all Ulva-containing pixels (Class 2, $N_{\mathrm{A}}, \alpha_{i}>0$ ) and Ulva-free pixels (Class $3, N_{\mathrm{W}}, \alpha_{i}=0$ ), in that grid cell in that month. Here $f$ represents the mean fractional algae coverage or areal density of Ulva. Without weighting each Ulva-containing pixel (i.e., let $\alpha_{i}=1.0$ ), Eq. (7) becomes $f=N_{\mathrm{A}} /\left(N_{\mathrm{A}}+N_{\mathrm{w}}\right)$. When $\alpha_{i}$ is 0.0 for all pixels, Eq. (7) becomes $f=0.0$. Eq. (7) is basically a linear mixing between Ulva-containing (after weighting) and Ulva-free pixels. Multiplied by a factor of $\left[0.025^{\circ} \times 110 \mathrm{~km} /\right.$ degree $\times 0.025^{\circ}$ $\times 110 \mathrm{~km} /$ degree $\times \cos (35)], f$ can be converted to algae coverage in $\mathrm{km}^{2}$. Integration of all grid cells will then lead to the total mean algae coverage for that month in $\mathrm{km}^{2}$.

For the annual mean Ulva coverage, Eq. (7) was used for all valid pixels falling in the grid cell for observations between May and August of the year.

\section{Results: Ulva distributions, areal coverage, and temporal changes}

All images were first visually inspected to determine the Ulva distributions under different observing conditions. While algae slicks could be visualized in the psuedo-RGB images, quantifying algae coverage requires the FAI images with the unmixing scheme. The maximum daily algae coverage (in $\mathrm{km}^{2}$ ) determined from individual images during each year between 2007 and 2015, both before and after umixing (Eq. (4)), is listed in Table 1. It is clear that after pixel unmixing, algae coverage shrunk to only a fraction of the original value $(<10 \%)$, suggesting that most of the algae-containing pixels are not completely covered by algae and a use of simple number of algae-containing pixels to estimate algae coverage area would lead to significant overestimates.

Fig. 1 shows the annual mean density distributions (i.e., percentage coverage) of Ulva (May-August) derived from the individual FAI images using the pixel unmixing scheme and statistics defined in Eqs. (4) and (7). The total area of pure algae coverage (in $\mathrm{km}^{2}$ ) during a particular month was calculated as the

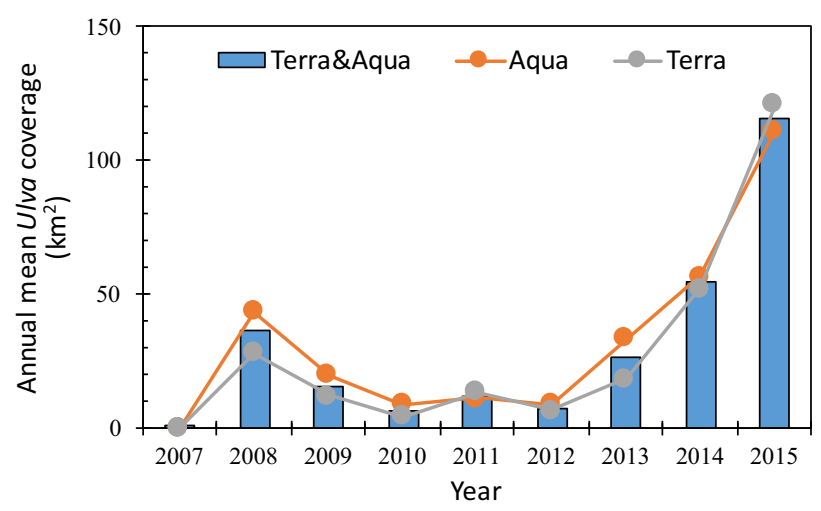

Fig. 2. Total annual (May-August) mean CoPA of Ulva between 2007 and 2015 derived from MODIS Terra (grey dots), MODIS Aqua (yellow dots), and Terra\&Aqua combined (blue bars). The total coverage was calculated as an integration of all grid cells shown in Fig. 1. (For interpretation of the references to color in the text, the reader is referred to the web version of this article.)

sum of Ulva coverage in all grid cells within the study area, from which long-term time-series was generated and analyzed.

The annual mean area of Ulva shows dramatic changes between 2007 and 2015 in both the algae distribution and the algae coverage (Figs. 1 \& 2). Hu et al. (2010) reported Ulva patches every year since 2000 in the Yellow Sea and East China Sea (ECS) through analyzing MODIS and Landsat FAI image series, but in the western YS (the study region in the current study) they did not report any Ulva patches before 2007. The results from this study also showed that in 2007, very little Ulva algae was found, while 2008 showed a sudden burst in Ulva bloom in the western YS, confirming the finding from previous studies. The bloom in 2008 caused serious environmental and economic problems in Qingdao ( $\mathrm{Hu}$ and $\mathrm{He}$, 2008), which also stimulated numerous follow-on studies to understand the bloom origins and driving factors. After 2008, some moderate blooms (i.e., $>10 \%$ but $<50 \%$ in the maximum daily CoPA referenced against maximum daily CoPA in 2008, Table 1) were found between 2009 and 2012, after which the bloom area increased annually to reach a maximum in 2015. Indeed, in 2015, the annual mean CoPA reached $116 \mathrm{~km}^{2}$, representing the largest Ulva bloom in this region (Xing et al., 2015b; SOA, 2016) and almost 4 times of the annual bloom size in 2008. However, in coastal waters near Qingdao (red circles in Fig. 1), CoPA appeared to be less in 2015 than in 2008 even 2015 had 4 times higher bloom size than 2008 , clearly indicating that both total bloom size and spatial distributions are important parameters for characterizing blooms and mitigating bloom impacts.

There is significant seasonality in the monthly mean CoPA, as shown in Figs. 3 \& 4 and Table 2. These results show that maximum

Table 1

Maximum daily CoPA (Coverage of Pure Algae) of Ulva during every year between 2007 and 2015.

\begin{tabular}{|c|c|c|c|c|c|}
\hline Date & ${ }^{\mathrm{a}}$ Weighted area $\left(\mathrm{km}^{2}\right)$ & ${ }^{\mathrm{b}}$ Unweighted area $\left(\mathrm{km}^{2}\right)$ & Ratio & ${ }^{\mathrm{C}}$ Garcia et al. (2013) & ${ }^{\mathrm{d}}$ Xing et al. (2015b) \\
\hline 17-June-07 & 2.2 & 93.8 & 0.02 & & 110 \\
\hline 25-June-08 & 508.0 & 6110.4 & 0.08 & & \\
\hline 15-July-09 & 180.2 & 4276.4 & 0.04 & $14.7-197.5$ & \\
\hline 21-June-10 & 76.1 & 1603.9 & 0.05 & & \\
\hline 13-June-11 & 133.1 & 2931.5 & 0.05 & & \\
\hline 4-June-12 & 70.9 & 1450.3 & 0.05 & & \\
\hline 29-June-13 & 516.4 & 5248.3 & 0.10 & & 1110 \\
\hline 28-June-14 & 551.0 & 5840.1 & 0.09 & & \\
\hline 21-June-15 & 1160.4 & 12035.8 & 0.10 & & \\
\hline
\end{tabular}

a Ulva coverage $\left(\mathrm{km}^{2}\right)$ after pixel weighting, i.e., CoPA.

b Ulva coverage $\left(\mathrm{km}^{2}\right)$ without pixel weighting (i.e., every algae-containing pixel was counted equally).

c Weighted area $\left(\mathrm{km}^{2}\right)$ using different thresholds in Garcia et al. (2013).

d Ulva coverage $\left(\mathrm{km}^{2}\right)$ without pixel weighting. 


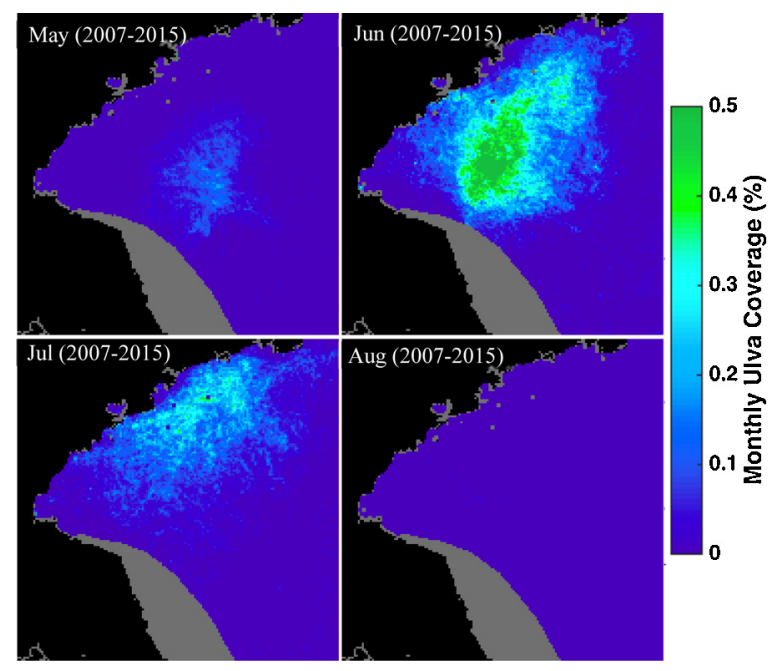

Fig. 3. Distributions of climatological monthly mean CoPA of Ulva between 2007 and 2015 in the western YS $\left(33^{\circ} \mathrm{N}-37^{\circ} \mathrm{N}\right.$ and $\left.119^{\circ} \mathrm{E}-123^{\circ} \mathrm{E}\right)$ derived from MODIS (Terra and Aqua) statistics. Black represents land, and grey means no data or shallow-water mask (Subei Shoal). A value of $0.5 \%$ means that for a $0.025^{\circ} \times 0.025^{\circ}$ grid cell $\left(\sim 6.2 \mathrm{~km}^{2}\right)$, mean CoPA between May and August was $0.5 \%$ of the cell $\left(\sim 0.03 \mathrm{~km}^{2}\right)$.

CoPA occurred in June of every year except 2009 and 2010. If the month of June were used to represent the annual distribution, the annual mean CoPA would be significantly higher than those shown in Figs. 1 and 2. On the other hand, similar to the annual changes, the monthly time series also showed profound year-to-year CoPA increases after 2012. For example, for the month of June, mean CoPA increased by 20 folds from $18.0 \mathrm{~km}^{2}$ in 2012 to $363.0 \mathrm{~km}^{2}$ in 2015. Furthermore, there appeared two distinctive periods of 2007-2012 and 2013-2015, respectively, with CoPA decreased and stabilized during the first period $\left(36.9 \pm 43.2 \mathrm{~km}^{2}\right.$ for June) but increased rapidly in the second period $\left(211.1 \pm 110.7 \mathrm{~km}^{2}\right.$ for June).

\section{Discussion}

\subsection{Uncertainties in Ulva coverage estimates}

Several methods have been used in the published literature to report Ulva coverage, which include (1) the water area "contaminated" by the algae; (2) the area of all algae-containing pixels; (3) effective algae coverage after unmixing of algae-containing pixels. While the first provides a useful measure of where the water may have algae presence and thus useful for planning field campaign
Table 2

Monthly mean CoPA $\left(\mathrm{km}^{2}\right)$ of Ulva between 2007 and 2015 from MODIS/Terra and MODIS/Aqua observations. Data are presented in graphical form in Fig. 4.

\begin{tabular}{llrrrrrrrr}
\hline & 2007 & 2008 & 2009 & 2010 & 2011 & 2012 & 2013 & 2014 & 2015 \\
\hline May & 0.0 & 22.0 & 0.0 & 0.0 & 0.0 & 8.0 & 0.0 & 21.1 & 36.4 \\
June & 0.2 & 129.7 & 23.1 & 11.3 & 39.2 & 18.0 & 102.2 & 168.1 & 363.0 \\
July & 0.3 & 21.6 & 52.2 & 15.5 & 17.3 & 2.5 & 44.9 & 73.1 & 153.0 \\
August & 0.0 & 0.1 & 0.0 & 0.0 & 0.0 & 0.5 & 0.0 & 0.0 & 0.1 \\
\hline
\end{tabular}

and preparing mitigation effort, it does not provide an accurate measure of the bloom size and is often subjective to visual judgment of individual image analysts. The second is an improvement, yet the result depends heavily on the sensor's pixel size (i.e., spatial resolution). The third provides the best measure of the pure algae coverage (i.e., CoPA) as it is an objective analysis once the appropriate thresholds are determined for $0 \%$ and $100 \%$ subpixel algae coverage.

The third method, however, is not trivial to implement, and perhaps this explains why most of the previously published works chose to use Method 1 or 2 to report the algae coverage or algae "contaminated" water area. The difficulty comes from two aspects: one is that the algae index must be linear with sub-pixel coverage, and the other is how to select the lower and upper bounds for $0 \%$ and $100 \%$ subpixel algae coverage, respectively. The use of FAI avoids the first problem because of its linear subtraction design (in comparison, the band ratio NDVI is not linear with sub-pixel coverage). The selection of the threshold values, on the other hand, is still challenging. In Hu et al. (2010), the mean FAI value from nearby land pixels (FAI $=0.02$ ) was chosen to be the upper bound and $\mathrm{FAI}=0.0$ was selected as the lower bound. Such threshold values led to the daily maximum CoPA of $1940 \mathrm{~km}^{2}$ in 2008 and $1600 \mathrm{~km}^{2}$ in 2009. In Garcia et al. (2013), image-based pixel statistics was used to determine the upper bound corresponding to top $0.01 \%$ or top $0.5 \%$ of all algae-containing pixels. Such reported CoPA ranged between $14.7-197.5 \mathrm{~km}^{2}$ for the image on 15 June, 2009 (Table 1). Our estimate on the same day was $161.0 \mathrm{~km}^{2}$ after pixel unmixing, within the top end of the suggested range. However, instead of using image statistics, the current study is based on field-measured algae spectra, thus providing a more mechanistic explanation on algae coverage.

Overall, maximum daily CoPA (Table 1 ) is significantly lower than reported in Hu et al. (2010) because of the much higher upper bound used in pixel unmixing in this study, and also significantly lower than all previously reported coverage when all algaecontaining pixels were treated the same (e.g., Xing et al., 2015b; Table 1). Interestingly, the ratio of CoPA to coverage of algaecontaining pixels appears to be separated for low and higher coverage: $5-6 \%$ when CoPA is $<160 \mathrm{~km}^{2}$ but $10-11 \%$ when CoPA is

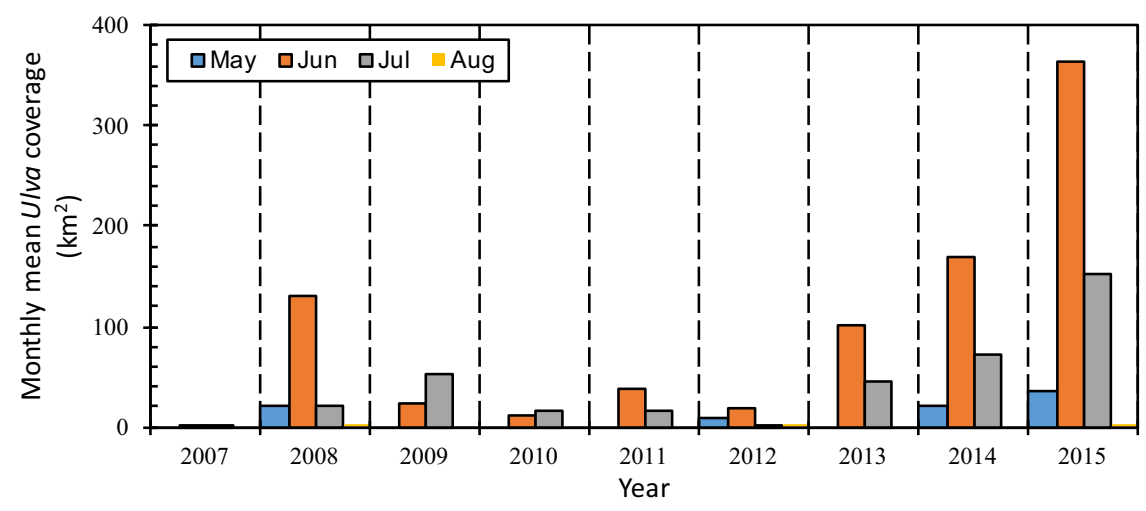

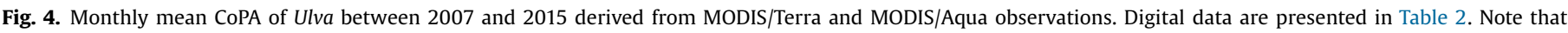
negligible Ulva was found in August in all years. 
$>500 \mathrm{~km}^{2}$. Such a result suggests that large amount of algae tends to aggregate more than smaller amount.

However, the estimates here are not error free either. As shown in Garcia et al. (2013), the most important single parameter is the upper bound threshold. Although a $\mathrm{FAI}_{\mathrm{H}}=0.15$ was selected from field measurements, it still contains some degrees of uncertainties. A sensitivity test showed that CoPA was nearly inversely proportional to $\mathrm{FAI}_{\mathrm{H}}$, which may change by $5-10 \%$. Such changes, however, will lead to a systematic bias than random variations in the long-term time series, thus will not affect the temporal patterns. Another factor influencing the estimates is wind, as Ulva tends to be more dissipated under high winds, making them less observable in MODIS imagery. Analysis of the same-day image pairs from MODIS/ Terra and MODIS/Aqua under different winds, respectively, showed that wind-induced changes were generally $<10 \%$ in the same day but increased to $>25 \%$ for two consecutive days when wind speed changed from 2.0 to $>4.0 \mathrm{~m} \mathrm{~s}^{-1}$ (Fig. 5), with higher winds always associated with lower algae coverage regardless of the sensors. Indeed, wind-induced turbulence may cause the algae to sink and disappear from satellite images. Unfortunately, of the entire period of 2013-2015, no cloud-free Landsat-8 satellite image could be found to estimate how much algae coverage MODIS may have underestimated. However, because there are no systematic changes in the long-term wind patterns, such wind-induced errors would lead to a systematic underestimation in the monthly and annual mean coverage, yet the underestimation will not affect the observed temporal patterns or trend.

One major difference between the current study and all previous studies is that multi-image statistics was used here to calculate mean CoPA at either monthly or annual scale, thus avoiding the typical problem of frequent cloud cover and sun glint. At monthly scale, each $0.025^{\circ} \times 0.025^{\circ}$ grid cell contained at least 1700 valid MODIS observations to make the calculation statistically meaningful (Fig. 6). Indeed, even when MODIS/Terra and MODIS/ Aqua were used to calculate the mean coverage separately, they both yielded results similar to the combined mean coverage (Fig. 2) at annual scale, suggesting the validity of the statistics.

Finally, it is noted that unlike conventional practices to validate ocean color observations of chorophyll a concentrations, it is nearly impossible to directly validate the observations presented in the composite images in Figs. 1-4 or in the individual images in Fig. 5 using field measurements. This is because the Ulva is very patchy, and nearly no MODIS pixels contain 100\% Ulva, not to mention several consecutive pixels required for a typical $3 \times 3$ or $5 \times 5$ homogeneity test. However, the linear unmixing and the image composition design in Eq. (7) circumvented this problem through statistics. As argued above, even though the absolute values may be off by $10 \%$, the relative spatial or temporal patterns of Ulva coverage and distribution should remain valid. Furthermore, once the CoPA numbers are derived, estimation of biomass will be straightforward using a calibration equation established from field measurements to convert areal coverage to biomass ( $\mathrm{Hu}$ et al., submitted)

\subsection{Factors leading to annual changes}

Without comprehensive and multi-disciplinary field studies to monitor the Ulva release from seaweed aquaculture, measure Ulva growth rate in different years, and understand what environmental factors led to changes in their growth rate, it is difficult to pin point the reasons of the inter-annual changes and long-term trend in the observed CoPA of Ulva. This is true for nearly all large-scale biological phenomena.

Although in general macroalgae blooms worldwide have increased due to coastal eutrophication (Smetacek and Zingone, 2013), for a particular region many factors can play a role. Among all environmental factors that could possibly influence Ulva amount, the following have been well documented by a number of studies: seaweed aquaculture size and production (which may determine the amount of Ulva initially released to the ocean), temperature, light, wind, and nutrient availability (Liu et al., 2009, 2013; Hu et al., 2010; Keesing et al., 2011; Xing et al., 2015b).

Indeed, a consensus among these studies is that Ulva originated from Subei Shoal (Fig. 1) where $>90 \%$ of China's $P$. yezoensis aquaculture is located. Once Ulva was released from the seaweed rafts, it was advected to the western YS following dominant currents, followed by rapid growth under favorable temperature, light, and nutrient availability. These environmental factors are presented in Figs. 6 and 7 in an attempt to understand the longterm changes in the Ulva patterns.

Fig. 7 shows a summary of the average water pollution in the western YS and seaweed aquaculture along Subei Shoal from 2001 to 2014. As reported before, the 2008 Ulva bloom was closely related to the increased seaweed aquaculture in 2008. However, further increases of aquaculture after 2008 did not lead to correspondent increases in Ulva coverage but the years of 20092012 were relatively stable. Note that the increased aquaculture from 2008 to 2012 was accompanied by increased water pollution level, as gauged by the AWCPI-NP (Fig. 7a). AWCPI-NP is an area weighted index for total inorganic nitrogen and phosphorous, representing water pollution (Xing et al., 2015b). Higher AWCPI-NP values indicate more pollution. While increases in the water pollution level are assumed to be associated with increases in nutrient availability for algae growth, could it be possible that certain nutrient species (e.g., N, P, Fe) may still be limited, thus causing the unparalleled trend in aquaculture, pollution, and Ulva coverage? Without statistically meaningful nutrient data and laboratory-based experiment to determine nutrient uptake rate, this can only remain a hypothesis to be tested. Analysis of other environmental factors did not lead to solid inference either. Fig. 8 shows the monthly anomaly SST and PAR over Subei Shoal for March-April, and monthly anomaly SST, PAR, precipitation, and wind over the western YS for May-August of 2007-2015. Note that SST in 2008 was lower than usual (Fig. 8a) but Ulva bloom first occurred in 2008, suggesting that low SST was not a limiting factor for Ulva growth. However, warmer-than-usual SST may promote Ulva growth. If this were the case, the warm SST during 20132015 could partially explain why CoPA was much higher than in previous years. The higher-than-usual PAR in 2013-2014, lowerthan-usual precipitation in 2013-2015, with lower-than-usual wind in 2014-2015, could be another reason to explain the overall higher CoPA than before 2013. However, all these environmental factors may work together in a complex, non-linear way to determine Ulva growth and biomass, and some of these factors may not be independent. For example, the strength of wind alone could explain $38 \%$ of the inter-annual CoPA variability between 2008 and 2014 for the month of June, but it could not explain CoPA in June 2015 (Fig. 9). Moreover, some small amount of macroalgae Ulva may drift and sink in other regions, e.g., in the East China Sea and the eastern part of the southern Yellow Sea (Hu et al., 2010; Xing et al., 2011; Son et al., 2015; Xing and Hu, 2016), thus reducing the bloom scale in the area of this study.

Adding to this complexity is the human impact, as local governmental agencies and environmental groups started to collect Ulva every year after 2008 when the Ulva bloom received wide national and international attention. The physical collection at sea represents one of the mitigation efforts. However, most of the collection was near Qingdao in order to maintain an algae-free environment for tourism. Although the exact amount of the Ulva collection is difficult to quantify, such mitigation efforts may represent one factor why there was less algae near Qingdao in 2015 than in 2008 even though June 2015 showed 3 times higher 

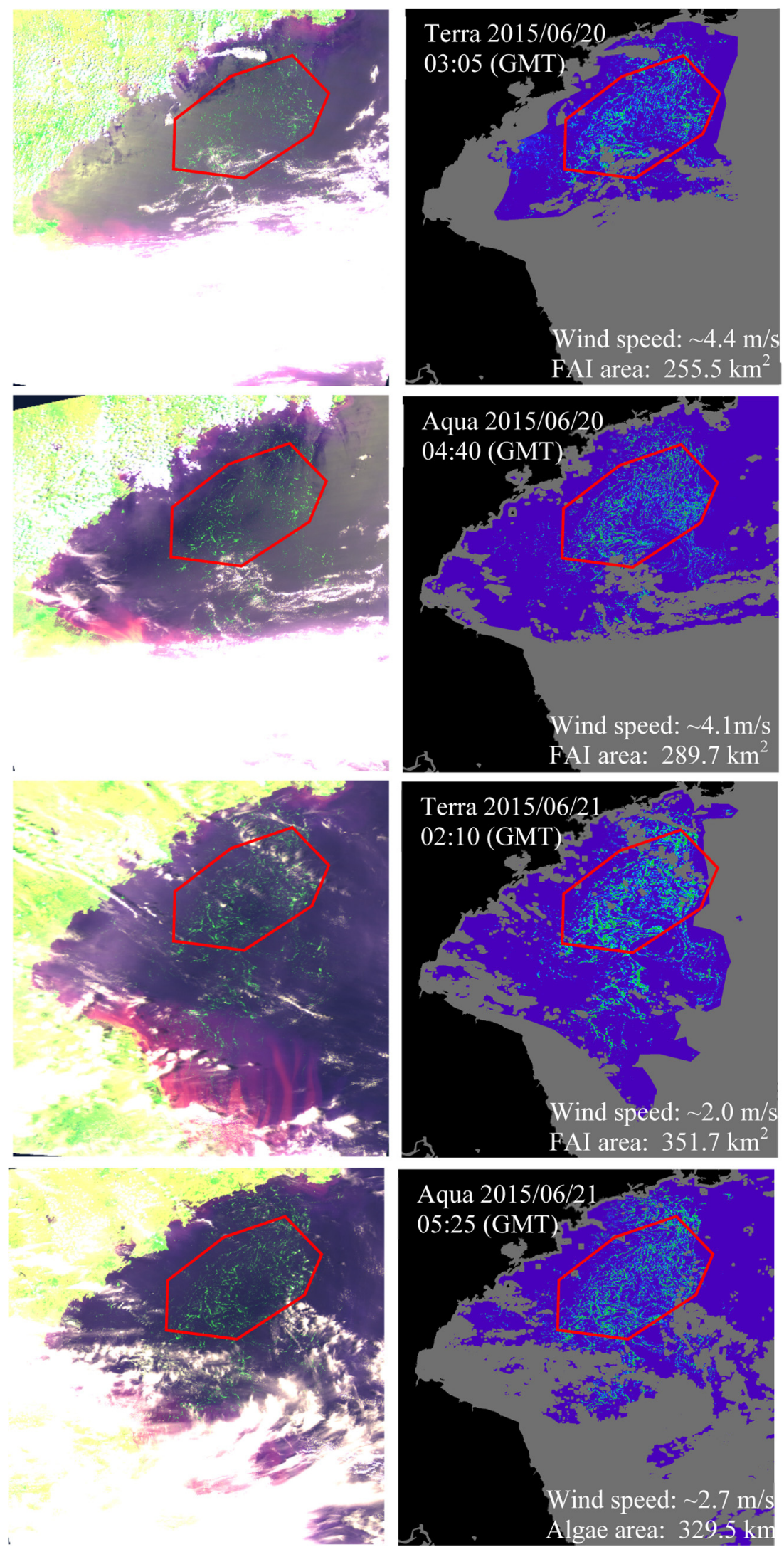
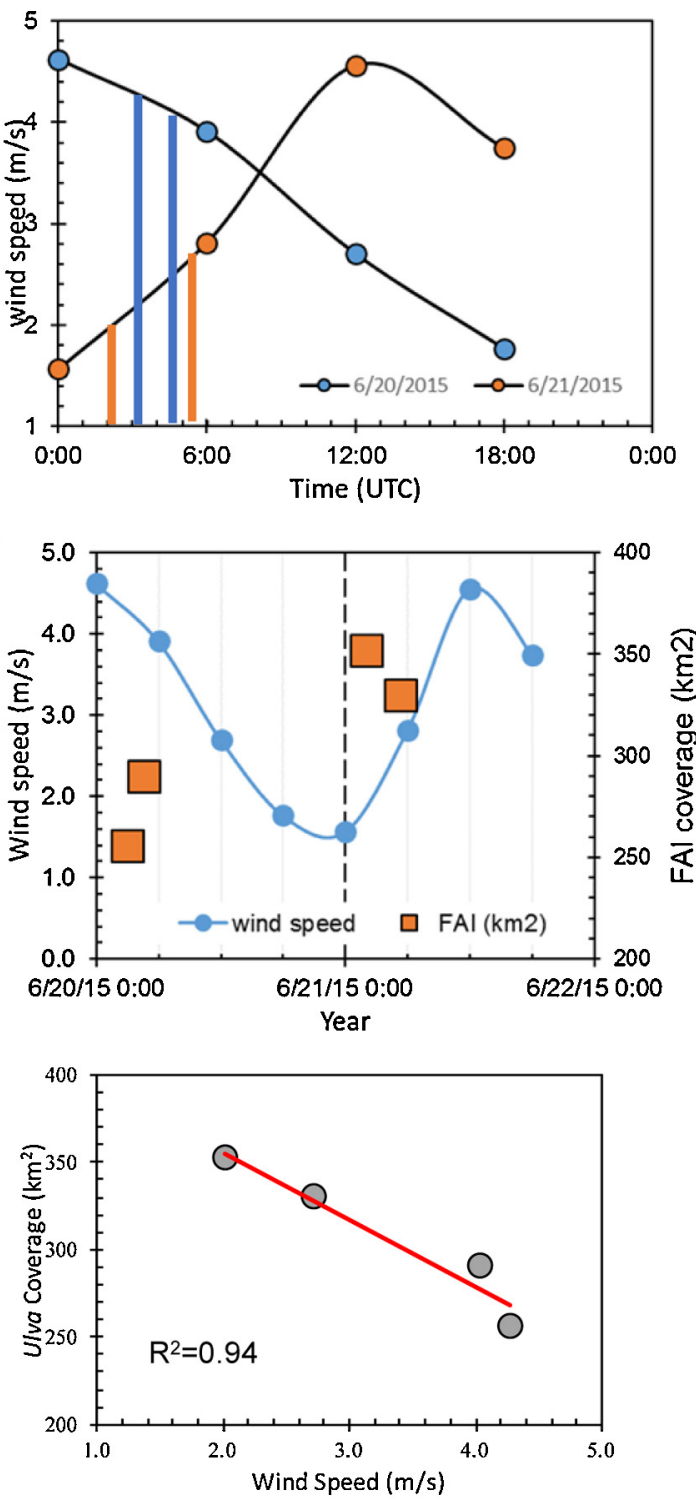

517

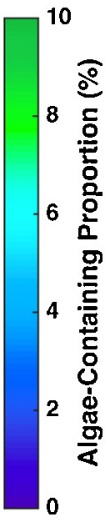

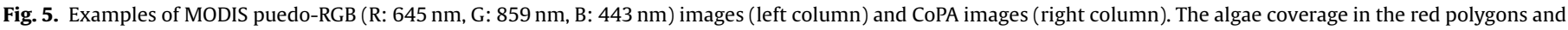

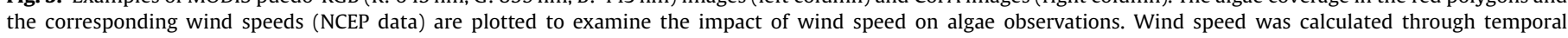

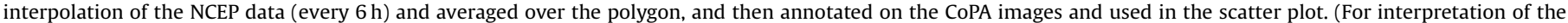
references to color in the text, the reader is referred to the web version of this article.) 

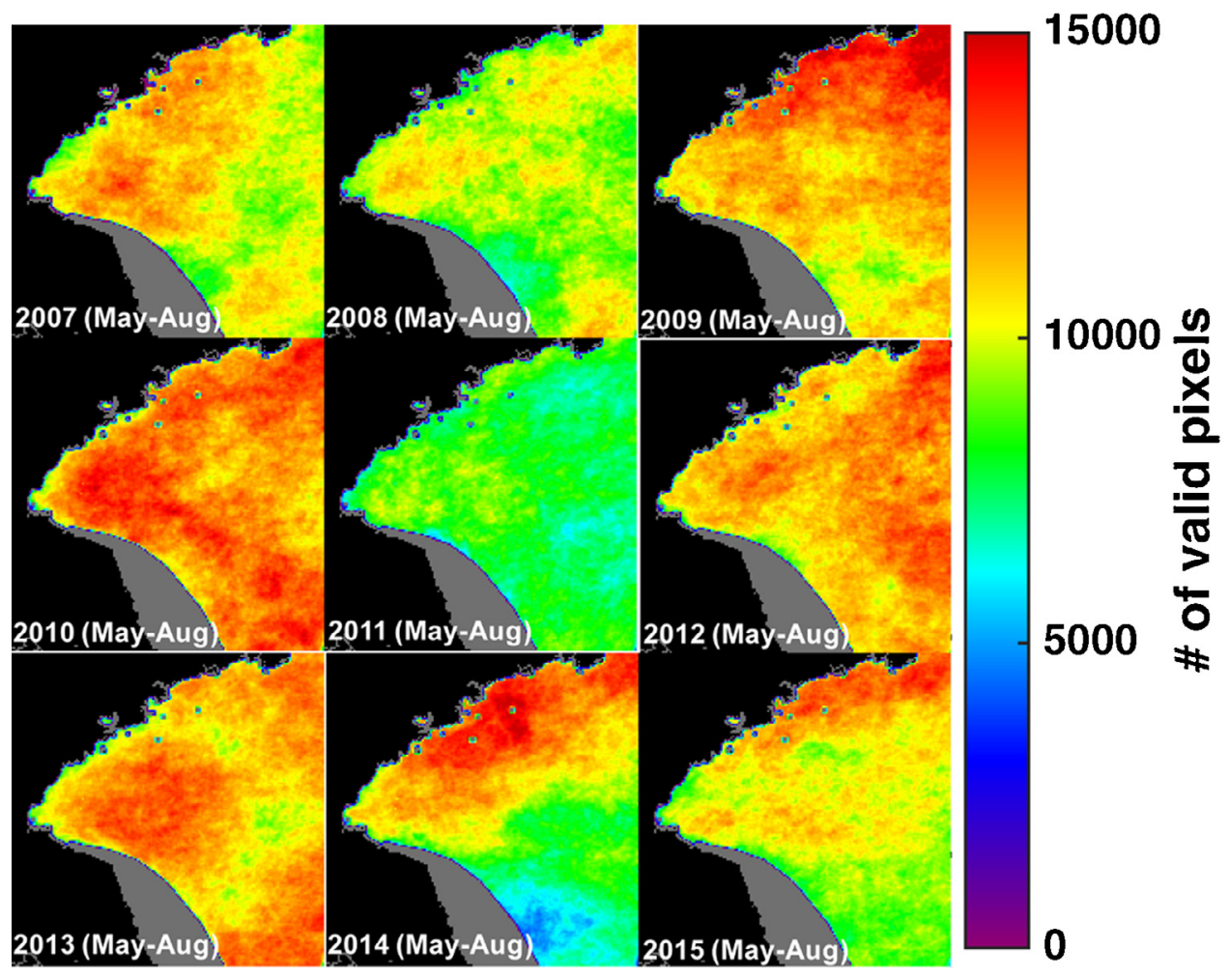

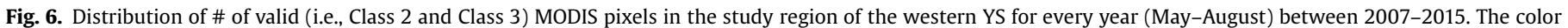

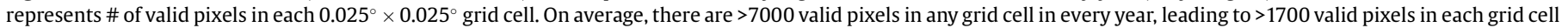
in an average month between May and August in any year.
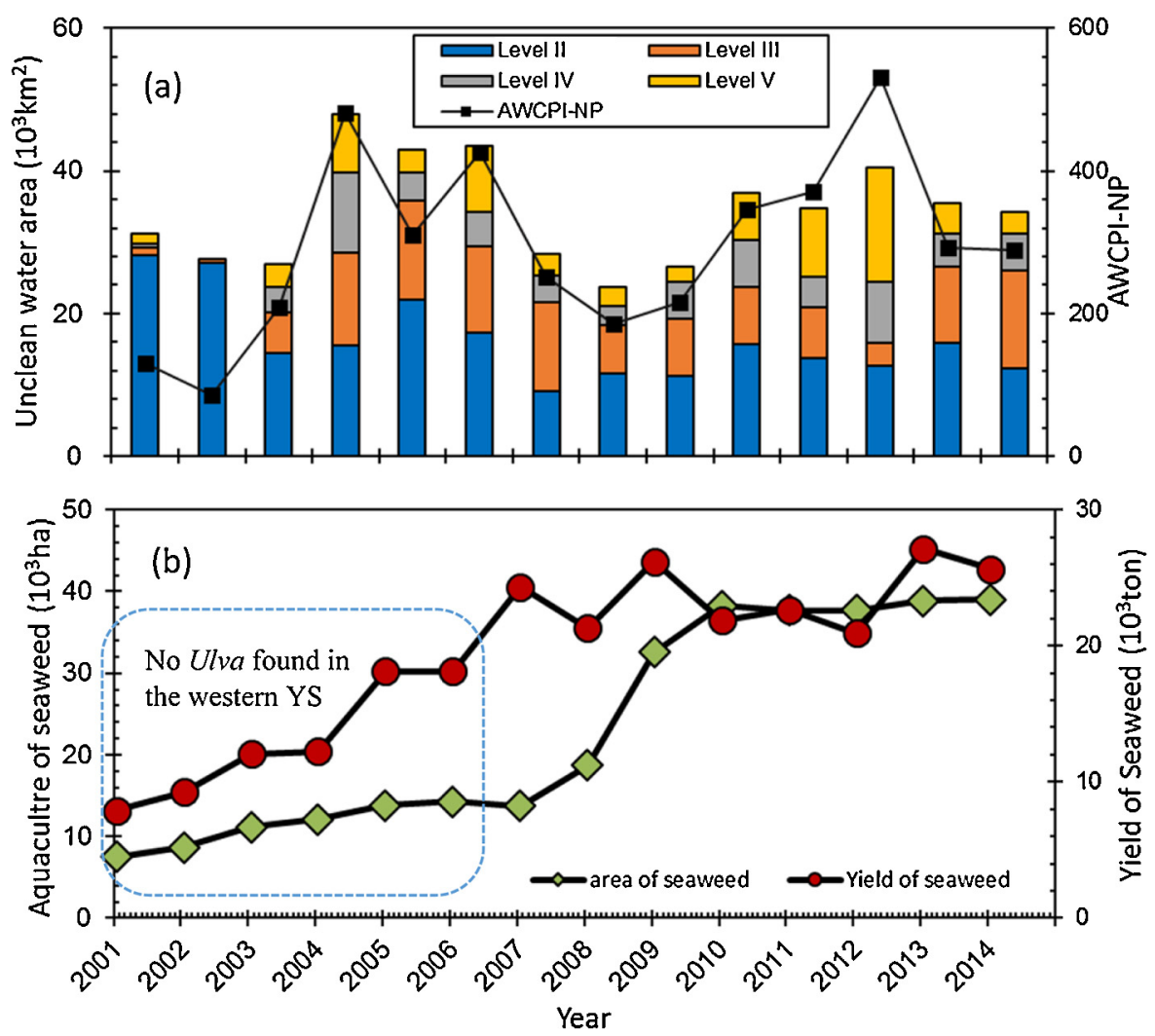

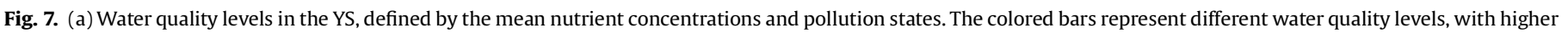

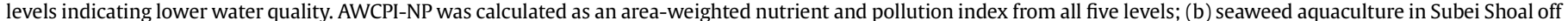

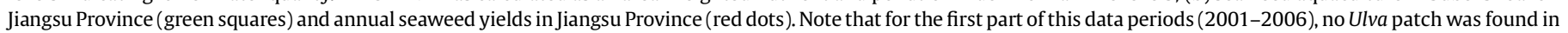

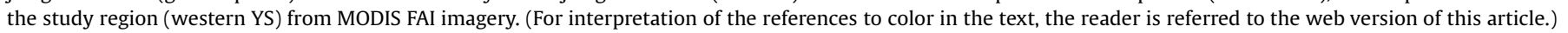



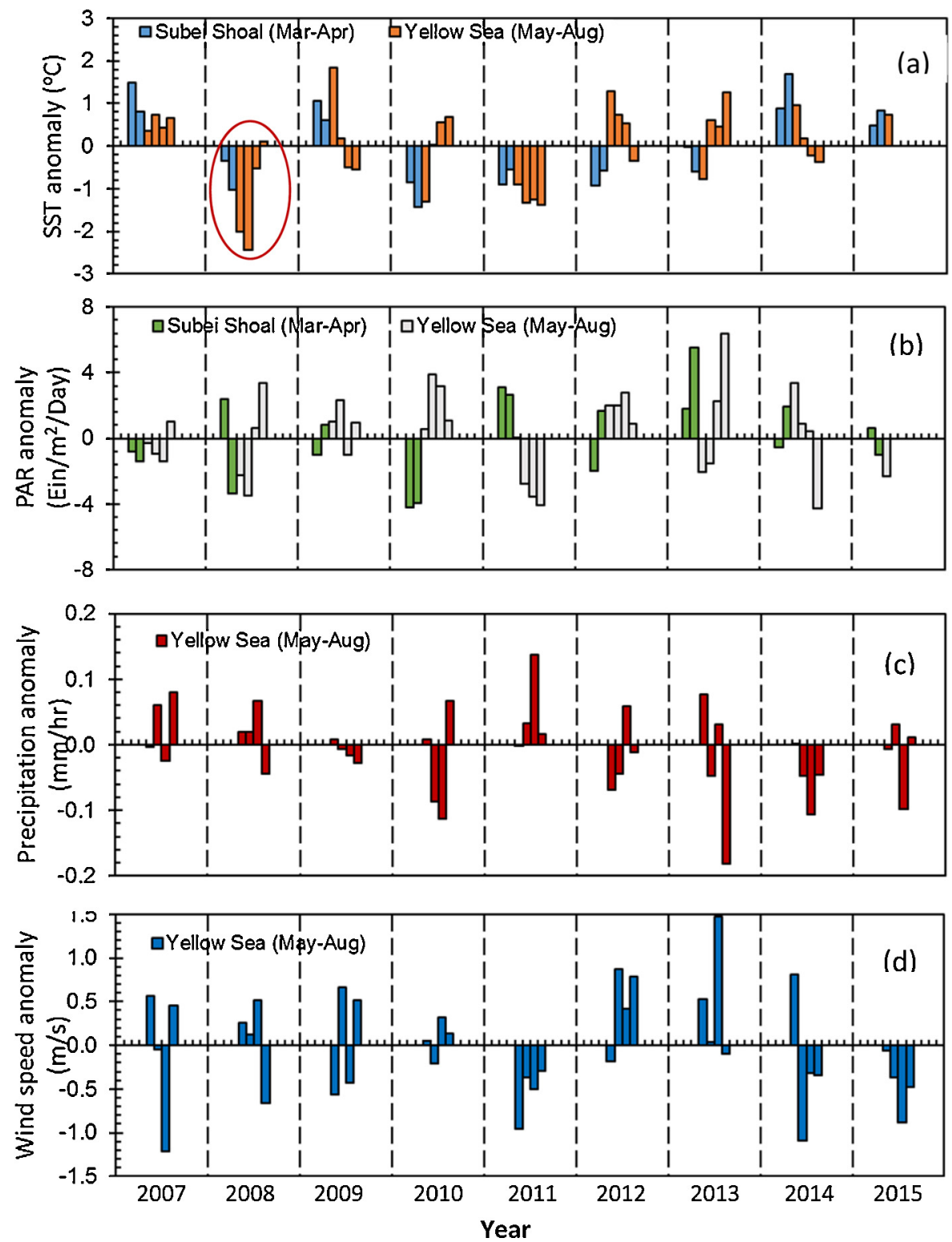

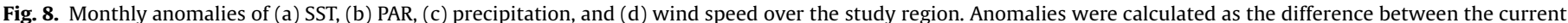
month and the climatological monthly mean between 2003 and 2015. Note that in (a) and (b), anomalies are presented for both Subei Shoal and western YS.

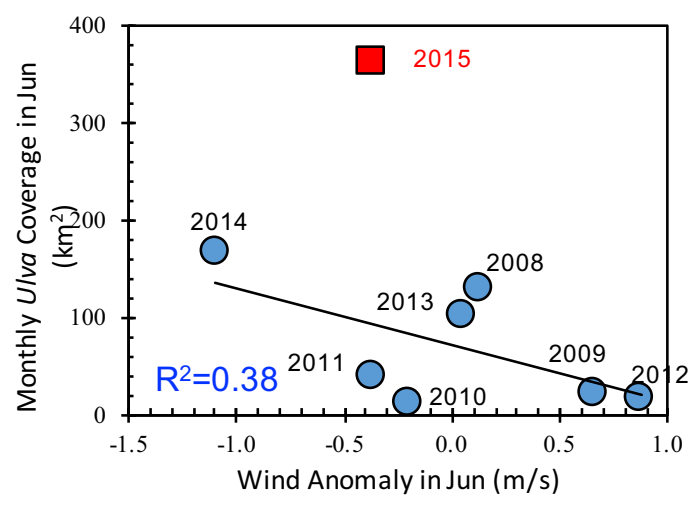

Fig. 9. Correlation between mean CoPA in June 2008-2014 and wind anomaly in June 2008-2014 (blue symbols). The data for 2015 is also shown as a red square, but not used in the correlation. (For interpretation of the references to color in the text, the reader is referred to the web version of this article.)
CoPA than June 2008. Another important factor is the windinduced currents, which determine the Ulva landing location (Lee et al., 2011; Keesing et al., 2011; Bao et al., 2015; Son et al., 2015). However, the landing location would not change the overall algae coverage estimates. As such, most of the inter-annual changes, especially in the later years (2013-2015), could not be explained by the mitigation efforts.

The interpretation here is therefore at the best speculative and far from conclusive. Clearly, further field and laboratory based research together with ecological modeling is required to fully understand Ulva biology and physiology to explain the observed patterns (e.g., Li et al., 2014; Yuanzi et al., 2014), before which a long-term forecasting of Ulva coverage is impossible.

\section{Conclusion}

Using MODIS observations and an objective method to delineate and quantify distribution and area coverage of the Ulva prolifera macroalgae, we derived the long-term patterns of Ulva 
CoPA (Coverage of Pure Algae) in the western Yellow Sea at both monthly and annual scales between 2007 and 2015, which showed the largest Ulva bloom in 2015. These results revealed long-term changes of CoPA that are previously unknown. Determining the reasons behind such changes is far more difficult than deriving satellite-based Ulva patterns, as Ulva distribution and abundance may be driven by a suite of environmental factors in a complex, non-linear way in addition to human mitigation efforts. A coordinated, multi-disciplinary effort is required to combine field, laboratory, and remote observations as well as ecological models to fully understand the long-term changes of Ulva abundance in the western Yellow Sea.

\section{Acknowledgements}

This work was supported by the National Natural Science Foundation of China (41576169), Chinese Academy of Sciences (XDA11020403, KZCX2-YW-Q07-01), Shandong Province Scientific Innovative Program (2007GG2QT06019), and The Programme of Introducing Talents of Discipline to Universities (B07034). We thank NASA for providing MODIS data and other satellite data, and thank the State Oceanic Administration (SOA) of China for providing nutrient and water pollution data. Two anonymous reviewers provided valuable comments and suggestions to help improve this manuscript, whose effort is appreciated. [CG]

\section{References}

Bao, M., Guan, W., Yang, Y., Cao, Z., Chen, Q., 2015. Drifting trajectories of green algae in the western Yellow Sea during the spring and summer of 2012. Estuar. Coast. Shelf Sci. 163, 9-16.

Campbell, J.W., Blaisdell, J.M., Darzi, M., 1995. In: Hooker, S.B., Firestone, E.R., Acker, J.G. (Eds.), Level-3 SeaWiFS Data Products: Spatial and Temporal Binning Algorithms. NASA Tech. Memo. 104566 vol. 32. NASA Goddard Space Flight Center, Greenbelt, Maryland. http://oceancolor.gsfc.nasa.gov/cms/SeaWiFS/ TECH_REPORTS/vol32_abs.

Cui, T.-W., Zhang, J., Sun, L.-E., Jia, Y.-J., Zhao, W., Wang, Z.-L., Meng, J.-M., 2012. Satellite monitoring of massive green macroalgae bloom (GMB): imaging ability comparison of multi-source data and drifting velocity estimation. Int. J. Remote Sens. 33, 5513-5527.

Garcia, R.A., Fearns, P., Keesing, J.K., Liu, D., 2013. Quantification of floating macroalgae blooms using the scaled algae index. J. Geophys. Res.: Oceans 118, 26-42.

He, M.-X., Liu, J., Yu, F., Li, D., Hu, C., 2011. Monitoring green tides in Chinese marginal seas. Handbook of Satellite Remote Sensing Image Interpretation: Applications for Marine Living Resources Conservation and Management. EU PRESPO and IOCCG, Dartmouth, Canada, pp. 111-124.

$\mathrm{Hu}, \mathrm{C} ., 2009$. A novel ocean color index to detect floating algae in the global oceans. Remote Sens. Environ. 113, 2118-2129.
Hu, C., 2011. An empirical approach to derive MODIS ocean color patterns under severe sun glint. Geophys. Res. Lett. 38, L01603. doi:http://dx.doi.org/10.1029/ $2010 \mathrm{gl045422.}$

Hu, C., He, M.-X., 2008. Origin and offshore extent of floating algae in Olympic sailing area? EOS AGU Trans. 89 (33), 302-303.

Hu, C., Li, D., Chen, C., Ge, J., Muller-Karger, F.E., Liu, J., Yu, F., He, M.X., 2010. On the recurrent Ulva prolifera blooms in the Yellow Sea and East China Sea. J. Geophys. Res.: Oceans 115, C05017.

Hu, L., Hu, C., He, M-X. Remote estimation of biomass of Ulva proliferamacroalgae in the Yellow Sea. Remote Sens. Environ. (submitted).

Keesing, J.K., Liu, D., Fearns, P., Garcia, R., 2011. Inter-and intra-annual patterns of Ulva prolifera green tides in the Yellow Sea during 2007-2009, their origin and relationship to the expansion of coastal seaweed aquaculture in China. Mar. Pollut. Bull. 62, 1169-1182.

Lee, J.H., Pang, I.C., Moon, I.J., Ryu, J.H., 2011. On physical factors that controlled the massive green tide occurrence along the southern coast of the Shandong Peninsula in 2008: a numerical study using a particle-tracking experiment. J. Geophys. Res.: Oceans 116 (C12).

Li, Y., Song, W., Xiao, J., et al., 2014. Tempo-spatial distribution and species diversity of green algae micro-propagules in the Yellow Sea during the large-scale green tide development. Harmful Algae 39, 40-47.

Liu, D., Keesing, J.K., Xing, Q., Shi, P., 2009. World's largest macroalgal bloom caused by expansion of seaweed aquaculture in China. Mar. Pollut. Bull. 58, 888-895.

Liu, D., Keesing, J.K., He, P., Wang, Z., Shi, Y., Wang, Y., 2013. The world's largest macroalgal bloom in the Yellow Sea, China: formation and implications. Estua. Coast. Shelf Sci. 129, 2-10.

Shi, W., Wang, M., 2009. Green macroalgae blooms in the Yellow Sea during the spring and summer of 2008. J. Geophys. Res.: Oceans 114.

Smetacek, V., Zingone, A., 2013. Green and golden seaweed tides on the rise. Nature $504,84-88$.

SOA (State Oceanic Administration of China), 2016. Bulletin of the Marine Environmental Status of China for the Year of 2015. http://www.soa.gov.cn/ zwgk/hygb/ (accessed 10.04.16).

Son, Y.B., Choi, B.-J., Kim, Y.H., Park, Y.-G., 2015. Tracing floating green algae blooms in the Yellow Sea and the East China Sea using GOCI satellite data and Lagrangian transport simulations. Remote Sens. Environ. 156, 21-33.

Wang, Z., Xiao, J., Fan, S., Li, Y., Liu, X., Liu, D., 2015. Who made the world's largest green tide in China?-an integrated study on the initiation and early development of the green tide in Yellow Sea. Limnol. Oceanogr. 60, 1105-1117.

Xing, Q., Hu, C., 2016. Mapping macroalgal blooms in the Yellow Sea and East China Sea using HJ-1 and Landsat data: application of a virtual baseline reflectance height technique. Remote Sens. Environ. 178, 113-126.

Xing, Q.G., Zheng, X.Y., Shi, P., Hao, J.J., Dingfeng, Y.U., Liang, S.Z., et al., 2011 Monitoring green tide in the Yellow Sea and the East China Sea using multitemporal and multi-source remote sensing images. Spectrosc. Spectr. Anal. 31 (6), 1644-1647.

Xing, Q., Hu, C., Tang, D., Tian, L., Tang, S., Wang, X.H., et al., 2015a. World's largest macroalgal blooms altered phytoplankton biomass in summer in the yellow sea: satellite observations. Remote Sens. 7 (9), 12297-12313.

Xing, Q., Tosi, L., Braga, F., Gao, X., Gao, M., 2015b. Interpreting the progressive eutrophication behind the world's largest macroalgal blooms with water quality and ocean color data. Nat. Hazards 78, 7-21.

Xu, Q., Zhang, H., Ju, L., Chen, M., 2014. Interannual variability of Ulva prolifera blooms in the Yellow Sea. Int. J. Remote Sens. 35, 4099-4113.

Yuanzi, H., Liang, H., Hailong, W., et al., 2014. Abundance and distribution of Ulva microscopic propagules associated with a green tide in the southern coast of the Yellow Sea. Harmful Algae 39, 357-364. 